\title{
Fluoride removal study using pyrolyzed Delonix regia pod, an unconventional adsorbent
}

\author{
M. Angelina Thanga Ajisha $\cdot$ K. Rajagopal
}

Received: 7 August 2012/Revised: 8 July 2013/Accepted: 14 December 2013/Published online: 8 January 2014

(C) Islamic Azad University (IAU) 2014

\begin{abstract}
Applicability of the new material pyrolyzed Delonix regia pod carbon for the removal of excess fluoride ions from the water that harm the human and the environment was studied. The adsorbent was characterized both physically and chemically. Surface chemistry characterization was done with $\mathrm{pH}$-drift method. Batch adsorption studies were carried out for the effect of $\mathrm{pH}$, dosage, contact time, initial fluoride concentration, temperature and interfering co-ions. The physicochemical properties and textural characters were analyzed. Equilibrium data were studied using Freundlich, Langmuir, Temkin and Dubinin-Radushkevich models, in which Freundlich isotherm was considered to be the best fit for the adsorbent. The sorption nature was studied using thermodynamic parameters which showed spontaneous, irreversible, stable and endothermic. The adsorption kinetics follows pseudo-second order. The mechanism of adsorption was determined from intraparticle diffusion model. Boyd plot showed that the adsorption of fluoride on the carbon was mainly governed by particle diffusion.
\end{abstract}

\footnotetext{
M. Angelina Thanga Ajisha ( $\square)$

Department of Civil Engineering, Government College

of Engineering, Tirunelveli 627007, India

e-mail: ajeeshain2010@gmail.com

K. Rajagopal

Francis Xavier College of Engineering,

Tirunelveli 627003, India
}

Keywords Batch - Defluoridation - Delonix regia . Isotherm · Thermodynamics · Kinetics · Mechanism

\section{Introduction}

Fluorosis was caused by intake of excess fluoride (greater than $1.5 \mathrm{ppm}$ ) in drinking water. Fluorosis was initially identified by discolored mottled teeth. Some places in Andhra Pradesh, Tamil Nadu, Karnataka, Kerala, Rajasthan, Gujarat, Uttar Pradesh, Punjab, Orissa and Jammu and Kashmir in India are affected by fluoride. It had been found in Tamil Nadu State that the fluoride concentration at Nilakkottai Block, Kadayam Block was 3 ppm and Palladam Taluk of Coimbatore District, Andipatti Block in Theni District was greater than $1.5 \mathrm{ppm}$ (Alagumuthu and Rajan 2008, 2010a, b; Viswanathan et al. 2008; Karthikeyan et al. 2010; Vennila et al. 2008). Many parts of Africa, Canada, China middle east and southern Asia have fluoride in groundwater (George et al. 2010).

World health organization (WHO) classified fluoride as one of the contaminants for human consumption in addition to arsenite and nitrate. Ground water of various parts of the world contain fluoride in increased concentration due to dissolution of fluorine from rocks and other minerals like fluorite, biotites and topaz. Industries also contaminate the water resources by discharging the wastewater containing $\mathrm{F}^{-}$(ranging from 10 to $1,000 \mathrm{mg} / \mathrm{L}$ ) from electroplating, ceramic, coal fired power station, beryllium extraction plants, brick and iron works and aluminum smelters. Worldwide nearly 200 million people depend on drinking water which has fluoride concentration more than $1.5 \mathrm{mg} / \mathrm{L}$ (Bhatnagar et al. 2011).

Fluoride removal studies were carried out by physical and chemical methods like precipitation and coagulation 
(Ghorai and Pant 2005), ion exchange (Meenakshi and Viswanathan 2007), reverse osmosis (Shen 2008), electrodialysis (Adhikary et al. 1989), but adsorption is found to be more suitable for defluoridation (Sairam Sundaram et al. 2009). Fluoride removal studies were done with various adsorbents. Fe-Ti oxide nano-adsorbent synthesized by co-precipitation which had a particle size of $5-7 \mathrm{~nm}$ had an adsorption capacity of $47 \mathrm{mg} / \mathrm{g}$ (Chen et al. 2012), iron-impregnated granular ceramics of surface area of $80.94 \mathrm{~m}^{2} / \mathrm{g}$ had an adsorption capacity of $2.16 \mathrm{mg} / \mathrm{g}$ of fluoride (Chen et al. 2011a), magnesia-loaded fly ash cenospheres of surface area $3.08 \mathrm{~m}^{2} / \mathrm{g}$ with average pore size of $2.98 \mathrm{~nm}$ has an adsorption capacity of $35.59 \mathrm{mg} / \mathrm{g}$ (Xiaotin et al. 2011), Kanuma mud of surface area $144.01 \mathrm{~m}^{2} / \mathrm{g}$ and pore volume of $0.17 \mathrm{~cm}^{3} / \mathrm{g}$ had an adsorption capacity of $1.112 \mathrm{mg} / \mathrm{g}$ (Chen et al. $2011 \mathrm{~b}$ ), bauxite of surface area $38 \mathrm{~m}^{2} / \mathrm{g}$ had adsorbed $5.16 \mathrm{mg} / \mathrm{g}$ of fluoride ion from contaminated groundwater (Sujana and Anand 2011), Fe(III)-loaded ligand exchange cotton cellulose (LECCA) of surface area $2.23 \mathrm{~m}^{2} / \mathrm{g}$ adsorbed $18.6 \mathrm{mg} / \mathrm{g}$ of fluoride ion from drinking water (Zhao et al. 2008), rare earth ions Sm(III), Ho(III), $\mathrm{La}(\mathrm{III}), \mathrm{Sc}(\mathrm{III})$ and $\mathrm{Lu}(\mathrm{III})$ prepared from orange waste by saponification reaction with lime water was studied, which has a maximum adsorption capacity of $0.60,0.92$, 1.06 and $1.22 \mathrm{mmol} / \mathrm{g}$ for Sc(III)-, Ho(III)-, La(III)- and Sm(III)-loaded adsorbent (Paudyal et al. 2012), but very limited study was done using agriculture waste and tree materials as sorbents, zirconium-impregnated cashew nut shell carbon of particle size $53 \mu \mathrm{m}$ has adsorbed $1.83 \mathrm{mg} /$ $\mathrm{g}$ of fluoride ion (Alagumuthu and Rajan 2010a, b), aluminum-coated rice husk of particle size $108 \mu \mathrm{m}$ and BET surface area $50.4 \mathrm{~m}^{2} / \mathrm{g}$ had a adsorption capacity of $15.08 \mathrm{mg} / \mathrm{g}$ (Ganvir and Das 2011), Moringa indica of particle size BSS 52 has an adsorption capacity of $3.3712 \mathrm{mg} / \mathrm{g}$ (Karthikeyan and Siva illango 2007), zirconium-impregnated groundnut shell of particle size greater than $53 \mu \mathrm{m}$ which has a saturation capacity of $1.26 \mathrm{mgF}^{-} / \mathrm{g}$ and also few other were also studied like coconut shell fiber carbon, coconut shell carbon, zirconium-impregnated coconut shell carbon (Bhatnagar et al. 2011).

In this study natural, waste and cheaper material from pod of Delonix regia an ornamental street tree was taken for removal of fluoride. Commercially available activated carbon was expensive for many countries due to the use of nonrenewable and expensive material such as coal and for this reason carbon like natural bamboo sawdust, sugarcane bagasse was experimented for the removal of proton, copper and arsenic. Nowadays research is going on for producing such cheaper and renewable carbon (Pehlivan et al. 2013; Tan et al. 2008; Zhao et al. 2012a, b).
Delonix regia tree grows in tropical and subtropical countries. It is known as gulmohar tree, flame of the forest, flamboyant tree, peacock flower, royal poincianas and flame tree. Delonix regia grows up to $5 \mathrm{~m}$ height and gives sprawling shade. The pods are dark brown and the length can be up to about $60 \mathrm{~cm}$ long and about $5 \mathrm{~cm}$ wide and the individual seeds are small. The seed pods are used as percussion instrument in Caribbean (Wikipedia 2011). The pods fall down after the bursting of seeds which are found on ground as wastes in most of the country, which can be converted into useful adsorbent.

The objectives of this study are to prepare activated carbon of higher pore volume and surface area from Delonix regia pod without any chemical treatment and to determine its effectiveness in removal of fluoride from aqueous solution. Physical, chemical and textural characterization was carried out for the pyrolyzed activated carbon. The equilibrium isotherm and thermodynamic, kinetics and adsorption mechanism studies were performed. No reports on use of Delonix regia pod-activated carbon have come into view for defluoridation. The novelty of this work is preparation of a good adsorbent for fluoride without no chemical impregnation or doping to give better efficiency. This work was performed at Environmental Engineering Laboratory, Government College of Engineering, Tirunelveli during December 2010-March 2011.

\section{Materials and methods}

Preparation of activated carbon

Delonix regia pods were collected and initially deseeded. It was washed with ordinary tap water 3-4 times and twice with distilled water. After washing, the pod was dried in the sunlight for a duration of about 4-5 h. The pod was then broken into pieces manually. The broken pods were kept inside muffle furnace using an air-tight cylindrical mold for pyrolysis. The pyrolysis process was done under the temperatures of 400, 500, 600,700 and $800{ }^{\circ} \mathrm{C}$ by keeping them in the furnace for $1 \mathrm{~h}$. The pyrolyzed carbon obtained at $400-700{ }^{\circ} \mathrm{C}$ produced color after the batch process, whereas at $800{ }^{\circ} \mathrm{C}$ carbon did not produce any color. Hence, the pyrolysis was carried out at $800{ }^{\circ} \mathrm{C}$ throughout the study. The carbon was referred to pyrolyzed Delonix regia pod carbon (PDPC). PDPC was pulverized and then sieved using 600, 300, 150 and 90- $\mu \mathrm{m}$ sieves. Particles retained on $300-\mu \mathrm{m}$ gave better results for fluoride removal than other sizes; hence, 300- $\mu \mathrm{m}$ retained particle was taken for the study. 
Preparation and analysis of fluoride solution

Fluoride stock solution of $1,000 \mathrm{mg} / \mathrm{L}$ was prepared by dissolving $2.21 \mathrm{~g}$ of GR grade sodium fluoride with $1 \mathrm{~L}$ double distilled water and stored in Tarson standard measuring flask (SMF) of $1,000 \mathrm{~mL}$ capacity. Further dilution was done from the $1,000 \mathrm{mg} / \mathrm{L}$ stock solution using SMF.

Fluoride ion concentration was determined by Orion ion-selective electrode (9609BNWP) using total ionic strength adjustment buffer (TISAB) to maintain $\mathrm{pH}$ 5.1-5.5 and retard interference effect of complexing ions. While measuring fluoride concentration, TISAB was added in equal proportion (1:1) with continuous stirring till a stable reading displayed in the meter (Karthikeyan and Siva Illango 2007).

Characterization and analysis of PDPC

PDPC was subjected to physical and chemical tests as per standard methods (APHA 2005) and the results were furnished in Table 1.

Surface chemistry characterization was done with $\mathrm{pH}$ drift method. The point of zero charge (ZPC) of the adsorbent is the $\mathrm{pH}$ at which the charge on the activated carbon surface is zero (Hameed et al. 2008). Tarson conical flask was taken with $0.01 \mathrm{~N} \mathrm{NaCl}$ solution and their $\mathrm{pH}$ values were adjusted between 1 and 12 using $0.01 \mathrm{~N} \mathrm{HCL}$ solution and $0.01 \mathrm{~N} \mathrm{NaOH}$. The initial $\mathrm{pH}$ was measured using $\mathrm{pH}$ meter (ELICO) and noted as $\mathrm{pH}$ initial, and to

Table 1 Characteristics of PDPC

\begin{tabular}{|c|c|c|c|}
\hline \multicolumn{2}{|c|}{ Physical characteristics } & \multicolumn{2}{|l|}{ Chemical characteristics } \\
\hline Parameter & Quantity & Parameter & Quantity \\
\hline $\begin{array}{l}\text { Effective particle } \\
\text { size }(\mu)\end{array}$ & 424 & $\% \mathrm{H}$ & 0.89 \\
\hline$\%$ moisture & 3.33 & $\% \mathrm{~N}$ & 0.67 \\
\hline Volatile matter & 5.54 & $\begin{array}{l}\text { Matter soluble in water } \\
\text { in } \%\end{array}$ & 0.662 \\
\hline Ash content & 7.886 & $\begin{array}{l}\text { Matter soluble in acid } \\
\text { in } \%\end{array}$ & 0.0113 \\
\hline $\begin{array}{l}\text { BET surface area } \\
\left(\mathrm{m}^{2} / \mathrm{g}\right)\end{array}$ & 54.8087 & $\mathrm{pH}(\mathrm{Zpc})$ & 8.5 \\
\hline $\begin{array}{l}\text { Total pore volume } \\
\left(\mathrm{cm}^{3} / \mathrm{g}\right)\end{array}$ & 0.027001 & $\mathrm{pH}$ of aqueous solution & 7.35 \\
\hline $\begin{array}{l}\% \text { weight loss by } \\
\text { ignition }\end{array}$ & 3.982 & $\begin{array}{l}\text { Decolorizing power } \\
(\mathrm{mg} / \mathrm{g})\end{array}$ & 16.5 \\
\hline Bulk density $(\mathrm{g} / \mathrm{cc})$ & 0.41833 & Iron content, ppm & 1.2044 \\
\hline $\mathrm{pH}$ & 9.17 & Iodine number(mg/g) & 818.63 \\
\hline$\% \mathrm{C}$ & 82.55 & & \\
\hline
\end{tabular}

each $\mathrm{pH}$-adjusted flask, $0.15 \mathrm{~g}$ of PDPC was added and kept for $48 \mathrm{~h}$ without shaking and the $\mathrm{pH}$ final was noted after $48 \mathrm{~h}$. This value was used to determine the point at which the adsorbent is inactive to adsorb ions, and hence, the adsorption is retarded above this $\mathrm{pH}$. The $\mathrm{pH} \mathrm{ZPC}$ of PDPC was found to be 8.5 .

Textural characterization like Brunauer-Emmett-Teller (BET) surface area, total pore volume and carbon-hydrogen-nitrogen $(\mathrm{CHN})$ percentage were determined using Porosimeter micormeritics ASAP 2020, CHN/O analyzer2400 and Perkin-Elmer instrument series II, respectively. Development of pores and surface texture were determined using scanning electron microscopy/energy dispersive analysis of X-rays (SEM/EDAX) FEI Quanta $200 \mathrm{~F}$, sophisticated analytical instrument facility (SAIF), IIT Madras. Fourier transform infrared (FTIR) analyses were done at Ayya Nadar Janaki Ammal College (ANJAC), Sivakasi.

\section{Batch studies}

Batch studies were performed using Tarson-make conical flask of $250 \mathrm{~mL}$ capacity with $100 \mathrm{~mL}$ test solution at room temperature. The flask with the test solution and adsorbent was shaken using wrist action shaker of Kemi make to study the various controlling parameters. After the desired contact time, the samples were filtered using Whatman filter paper no. 2 and the filtrate was analyzed for its residual fluoride concentration. Batch study was performed to find out the optimal conditions, and the study was carried out by varying $\mathrm{pH}$, adsorbent dosage, contact time and temperature. The influence of anions like chloride, nitrate, sulfate, bicarbonate and cations like calcium, magnesium on defluoridation efficiency were verified using PDPC. The concentration of co-existing ions varied from (50 to $300 \mathrm{ppm}$ ) and with initial fluoride concentration of $10 \mathrm{mg} / \mathrm{L}$.

The amount of fluoride ion removed in percentage was calculated using the following equation

$\%$ Fluoride removal $=\left[\left(C_{i}-C_{e} / C_{i}\right] \times 100\right.$

where, $C_{i}$ is the initial fluoride ion concentration $(\mathrm{mg} / \mathrm{L})$, $C_{e}$ is the equilibrium concentration of fluoride ion in solution after adsorption $(\mathrm{mg} / \mathrm{L})$.

The relative standard deviation (RSD) can be calculated by dividing the standard deviation by arithmetic mean

$\mathrm{RSD}=[\operatorname{Standard} \operatorname{deviation}(\mathrm{S}) / \operatorname{arithmetic~mean~(A.M.)}]$ $\times 100$

$N$ is number of measurements carried out, $x_{i} \mathrm{~s}$ are the observed data. 


\section{Adsorption isotherm}

In order to determine the nature of interaction between the adsorbate and adsorbent, adsorption isotherms were performed. The fluoride distribution between the solid and liquid phase is a measure of the position of equilibrium in the adsorption process. There are several isotherm models, and the obtained equilibrium data were fitted using Freundlich, Langmuir, Temkin and Dubinin-Radushkevich models in their nonlinear forms. The best isotherm model was evaluated by calculating correlation coefficient $R^{2}$ values.

\section{Results and discussion}

\section{Effect of $\mathrm{pH}$}

The most important fact that controls the adsorption of ions is the $\mathrm{pH}$ of the aqueous solution. The effect of $\mathrm{pH}$ was studied in the $\mathrm{pH}$ range of $1-12$ at a constant initial fluoride concentration of $10 \mathrm{mg} / 1,000 \mathrm{~mL}$ and adsorbent dosage of $1.5 \mathrm{~g}$. The $\mathrm{pH}$ was adjusted using $1 \mathrm{~N} \mathrm{HCl}$ and $1 \mathrm{~N} \mathrm{NaOH}$. The data obtained for percentage removal of fluoride for various $\mathrm{pH}$ values were presented in Table 2. From Table 2, it was observed that the maximum percentage removal of fluoride was $97.9 \%$ at $\mathrm{pH} 2$ (acidic). Below and above $\mathrm{pH} 2$, the removal percentage was less than $97.9 \%$. The initial $\mathrm{pH}$ of the fluoride solution was 6.7, and it was adjusted to $\mathrm{pH} 2$ by adding $2.1 \mathrm{~mL}$ of $1 \mathrm{~N} \mathrm{HCl}$. The anion fluoride adsorption is coupled with a release of $\mathrm{OH}^{-}$ ions, so adsorption of $\mathrm{F}^{-}$on PDPC surface is probably favored in low $\mathrm{pH}$; the same effect was seen in defluoridation using alum-impregnated activated alumina which was studied by Tripathy et al. (2006). The fluoride adsorption was found to be high at acidic medium due to the strong columbic force between positive charged surface and the fluoride ions. At alkaline condition, the fluoride adsorption was low; it may be due to repulsion between negatively charged surface and fluoride ions. Fluoride removal percentage has been decreased after $\mathrm{pH} 3.5$, and this may be due to increasing electrostatic repulsion between negatively charged surface sites of PDPC and fluoride. Similar effect was studied by Tembhurkar and Dongre (2006) for powdered activated charcoal. For further studies, pH 2 was taken as it gave the maximum fluoride removal. From Table 2, it can be observed that for increase in $\mathrm{pH}$, the percentage removal is going on increasing up to a value 2.0 and afterward there is gradual reduction in the percentage removal up to 2.4. However, after 2.4, there is a sudden fall percentage removal from 96 to 71,64 and 51
Table 2 Effect of $\mathrm{pH}$

\begin{tabular}{llllll}
\hline Initial $\mathrm{pH}$ & $C_{e}(\mathrm{mg} / \mathrm{L})$ & PFR & Initial $\mathrm{pH}$ & $C_{e}(\mathrm{mg} / \mathrm{L})$ & PFR \\
\hline 1.0 & 0.79 & 92.1 & 2.5 & 2.9 & 71 \\
1.1 & 0.69 & 93.1 & 2.6 & 3.6 & 64 \\
1.2 & 0.64 & 93.6 & 2.7 & 4.9 & 51 \\
1.3 & 0.57 & 94.3 & 2.8 & 8.5 & 15 \\
1.4 & 0.53 & 94.7 & 2.9 & 8.74 & 12.6 \\
1.5 & 0.5 & 95 & 3.0 & 8.98 & 10.2 \\
1.6 & 0.41 & 95.9 & 4.0 & 9.56 & 4.4 \\
1.7 & 0.34 & 96.6 & 5.0 & 9.64 & 3.6 \\
1.8 & 0.28 & 97.2 & 6.0 & 9.66 & 3.4 \\
1.9 & 0.26 & 97.4 & 7.0 & 9.72 & 2.8 \\
2.0 & 0.21 & 97.9 & 8.0 & 9.86 & 1.4 \\
2.1 & 0.22 & 97.8 & 9.0 & 9.88 & 1.2 \\
2.2 & 0.33 & 96.7 & 10.0 & 9.94 & 0.6 \\
2.3 & 0.36 & 96.4 & 11.0 & 10 & 0 \\
2.4 & 0.4 & 96 & 12.0 & 10 & 0 \\
\hline
\end{tabular}

$C_{e}$ equilibrium concentration of fluoride after adsorption in $\mathrm{mg} / \mathrm{L}$, $P F R$ percentage fluoride removal in percentage

for $\mathrm{pH}$ increase by 2.4-2.5, 2.6 and 2.7, respectively. Again, a steep fall can be seen from 51 to 15 for increase in $\mathrm{pH}$ from 2.7 to 2.8 and the same trend can be observed from 2.8 to $12 \mathrm{pH}$. Hence, to check the consistency, the percentage removal has been taken up to $96 \%$ corresponding to a pH value of 2.4. From Eq. (2), RSD value calculated which was 1.86 which shows the data to be consistent.

\section{Effect of dosage}

The effect of PDPC dosage was studied from 0.5 to $5 \mathrm{~g}$ for initial fluoride concentration of $10 \mathrm{mg} / \mathrm{L}$ for contact time of $5 \mathrm{~h}$. The $\mathrm{pH}$ was maintained as 2 for all dosages. It was observed that fluoride removal increased with the adsorbent dosage and the maximum removal of $98.4 \%$ was observed at a dosage of $1.5 \mathrm{~g}$. As the dosage increases, more adsorbents with active sites and surface area may be the reason for higher removal efficiency. Therefore, $1.5 \mathrm{~g} /$ $100 \mathrm{~mL}$ dose was optimized for further studies as no significant progress in the removal was observed on further increase in adsorbent dose. The RSD value was 10.22.

\section{Effect of contact time}

The fluoride removal studies were done by varying the contact time with fixed dosage of $1.5 \mathrm{~g} / 100 \mathrm{~mL}$ and initial fluoride concentration of $10 \mathrm{mg} / \mathrm{L}$ and $\mathrm{pH} 2$. The observed data was presented in Fig. 1, which shows the removal 


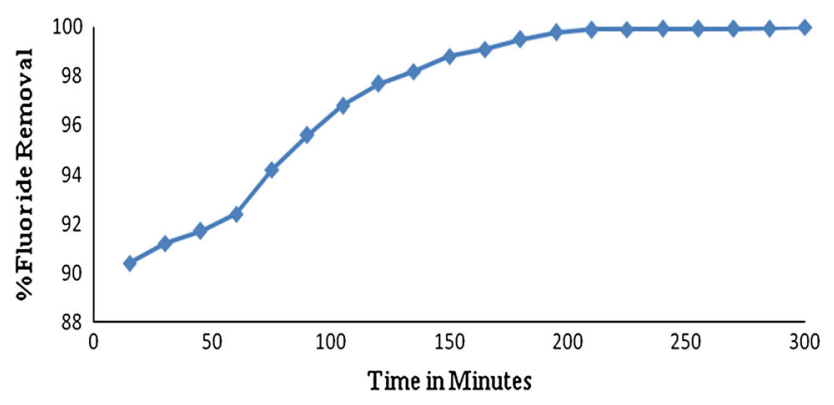

Fig. 1 Effect of contact time on fluoride removal

increases with time and the removal was found to vary from 98.4 to $99.86 \%$ for the contact time of 15 to $300 \mathrm{~min}$. Further studies have been carried out by keeping $300 \mathrm{~min}$ as the contact time. The RSD value was 3.48 .

\section{Effect of initial concentration}

The effect of initial concentration was studied ranging from 2 to $10 \mathrm{mg} / \mathrm{L}$ with an adsorbent dosage of $1.5 \mathrm{~g}$, contact time of $300 \mathrm{~min}$ and $\mathrm{pH}$ 2. This effect was studied under room temperature of $28 \pm 1{ }^{\circ} \mathrm{C}$. The removal percentage was above $97 \%$ for all the initial concentration. The adsorption capacity was better for low initial concentration of fluoride than at higher concentration of fluoride. The RSD value was 0.66 , which confirms consistency.

\section{Effect of temperature}

The temperature effect was studied with $30,40,50$ and $60{ }^{\circ} \mathrm{C}$ in a water bath incubator shaker with the optimal condition of $\mathrm{pH}$ 2, adsorbent dosage $1.5 \mathrm{~g}$ and with contact time $300 \mathrm{~min}$. It was observed that the increase in temperature increases the percentage removal of fluoride from Table 3 . This may be due to stronger adsorptive forces between PDPC and fluoride ion, and hence, the temperature is a favorable factor for fluoride sorption (Murugan and Subramanian 2006). The removal efficiency for all the temperatures were greater than $98.4 \%$ and very good removal efficiency of $99.4 \%$ was found at 50 and $60{ }^{\circ} \mathrm{C}$. The RSD values calculated for all the temperatures show uniformity in the results as it ranges between 0.045 and 0.197 .

\section{Effect of influence of co-ions}

The influence of anions such as chloride, nitrate, bicarbonate, sulfate and cations such as calcium, magnesium for fluoride removal was experimentally verified by adding $\mathrm{NaCl}, \mathrm{NaNO}_{3}, \mathrm{NaHCO}_{3}, \mathrm{Na}_{2} \mathrm{SO}_{4}, \mathrm{CaCO}_{3}$ and $\mathrm{MgCl}_{2} \cdot 6 \mathrm{H}_{2} \mathrm{O}$ salts. The concentration of co-ions varied
Table 3 Effect of temperature

\begin{tabular}{|c|c|c|c|c|c|c|c|c|}
\hline \multirow{2}{*}{$\begin{array}{l}C_{i} l \\
\text { temp. }\end{array}$} & \multicolumn{2}{|l|}{$30^{\circ}$} & \multicolumn{2}{|l|}{$40^{\circ}$} & \multicolumn{2}{|l|}{$50^{\circ}$} & \multicolumn{2}{|l|}{$60^{\circ}$} \\
\hline & $C_{e}$ & PFR & $C_{e}$ & PFR & $C_{e}$ & PFR & $C_{e}$ & PFR \\
\hline 2 & 0.029 & 98.6 & 0.023 & 98.9 & 0.016 & 99.2 & 0.012 & 99.4 \\
\hline 4 & 0.048 & 98.8 & 0.044 & 98.9 & 0.024 & 99.4 & 0.021 & 99.48 \\
\hline 6 & 0.090 & 98.5 & 0.065 & 98.9 & 0.042 & 99.3 & 0.04 & 99.33 \\
\hline 8 & 0.13 & 98.4 & 0.089 & 98.9 & 0.072 & 99.1 & 0.054 & 99.3 \\
\hline 10 & 0.16 & 98.4 & 0.12 & 98.8 & 0.098 & 99.02 & 0.059 & 99.4 \\
\hline
\end{tabular}

$C_{i}$ initial concentration of fluoride ion in $\mathrm{mg} / \mathrm{L}, P F R$ percentage fluoride removal in $\%, C_{i}$ initial concentration of fluoride ion in $\mathrm{mg} / \mathrm{L}$

from 50 to $300 \mathrm{mg} / \mathrm{L}$ at an interval of $50 \mathrm{mg} / \mathrm{L}$ and initial fluoride concentration was kept at a constant level of $10 \mathrm{mg} / \mathrm{L}$. It was found that no remarkable interference was observed with the co-ions for the removal of fluoride ion. The efficiency of removal is greater than $90 \%$ in all the cases except with $300 \mathrm{mg} / \mathrm{L} \mathrm{CaCO}_{3}$, which gave a removal efficiency of only $42 \%$. It was also confirmed by RSD which ranges from 0.009 to 0.332 for all the co-ions added except for $\mathrm{Ca}^{2+}$ which was 25.43 which is not in agreement.

\section{FTIR analysis}

FTIR serves for the identification of the organic functional groups on the surface of the adsorbent. FTIR spectrum before and after adsorption of fluoride in PDPC were presented in Fig. 2. The peaks were shifted or disappeared and new peaks were detected in the spectrum, and these changes show the presence of various functional groups in PDPC. The spectrum before adsorption is found to be $3,415.62 / \mathrm{cm}$ which has stretched to $3,427.62 / \mathrm{cm}$ after adsorption and this may be due to the stretching vibration of hydroxyl group of activated carbon. Similar trend was observed for zirconium-impregnated cashew nut shell carbon, where the stretching frequency of 3,626-3,451 $\mathrm{cm}^{-1}$ (Alagumuthu and Rajan 2010a, b) and for zirconium-impregnated ground-nut shell (Alagumuthu and Rajan 2010a, b) implies the involvement of hydroxyl group in the fluoride adsorption. The strong adsorption band at 2,854.74/cm (C-H stretching) and 2,009.89/cm shows a strong $\mathrm{C}=\mathrm{O}, \mathrm{C}=\mathrm{C}$ bond. Bands in $1,381.08 / \mathrm{cm}$, $1,019.41 / \mathrm{cm}$ show a strong $\mathrm{C}-\mathrm{O}, \mathrm{O}-\mathrm{H}$ bond. New peaks are formed $1,464.02 / \mathrm{cm}(\mathrm{C}-\mathrm{H}$ bond) $1,584.57 / \mathrm{cm}$, (phenolic group), $1,693.156 / \mathrm{cm}$ (carbonyl group stretching from aldehyde and ketone) and $1,123.57 / \mathrm{cm}(\mathrm{C}-\mathrm{O}, \mathrm{O}-\mathrm{H}$ bond). Stretching of bonds in $650-400 / \mathrm{cm}$ is due to $\mathrm{F}-\mathrm{O}$ bond vibration in which $\mathrm{SO}_{2}$ and $\mathrm{NO}_{2}$ has escaped out. It is 
用 SHIMADZU

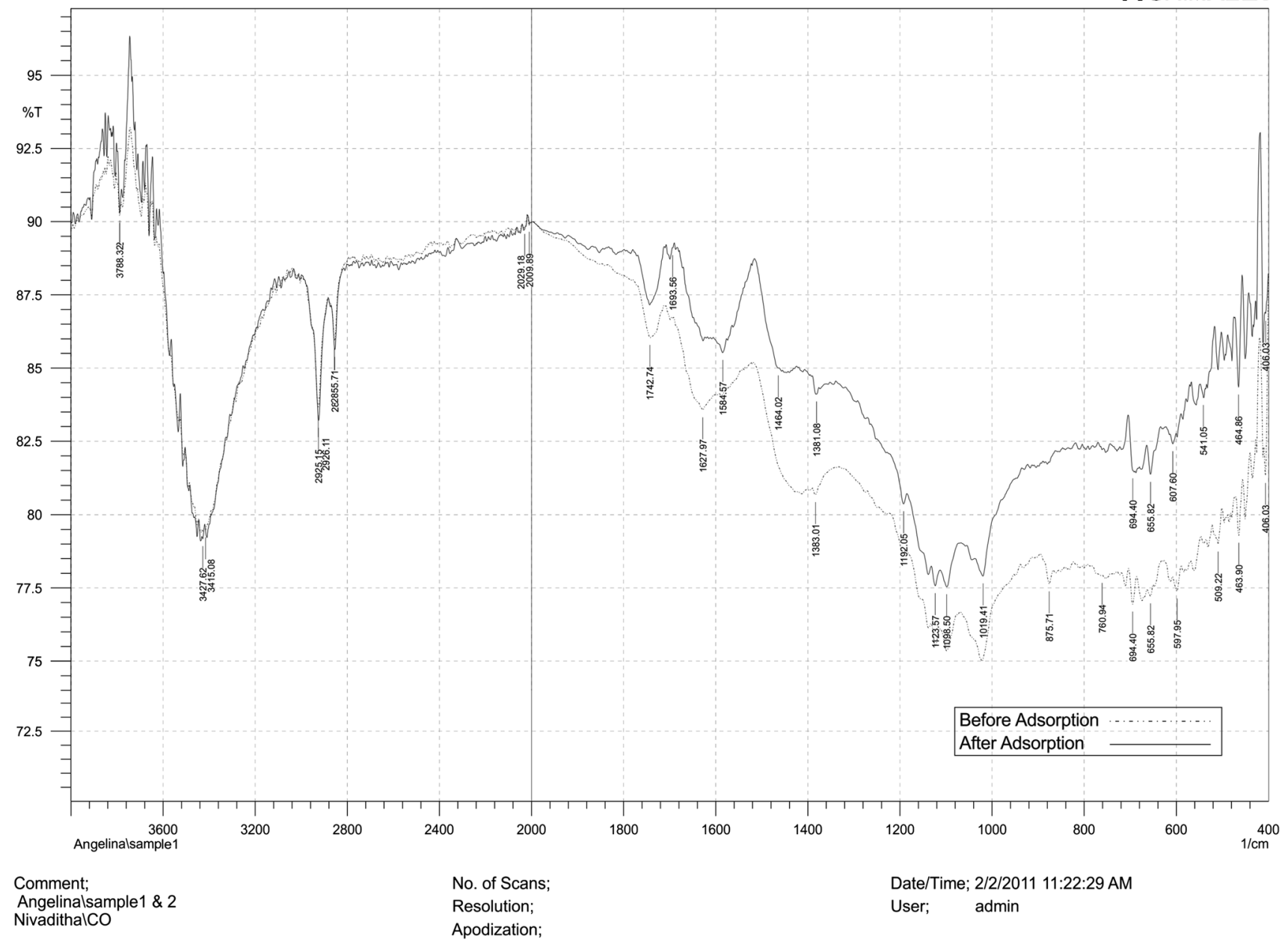

Fig. 2 FTIR analysis before and after adsorption of fluoride on PDPC

inferred from the spectrum that the adsorbent contain hydrocarbon with hydroxyl groups (Gonzalez et al. 2008; Nadeem et al. 2009; Mungapati et al. 2009; Meenakshi sundaram et al. 2011).

\section{SEM and EDAX analysis}

The surface texture, porosity and the percentage chemical composition of adsorbents were clearly revealed in SEM/ EDAX analysis. SEM micrographs before and after adsorption of fluoride in PDPC were shown in Fig. 3a, b, respectively. Before adsorption, macropores are honeycombed structure with size range of $32-36.5 \mu \mathrm{m}$. Micropores and mesopores were also found in the adsorbent. After adsorption, white patches were observed in the pores and also the pore sizes have been reduced to a range from its original size range of $32-36.5$ to $3-18 \mu \mathrm{m}$ which indicated the adsorption of fluoride ions on the pores.
For better characterization of the adsorbent and to know the elements present in PDPC, energy dispersive $\mathrm{X}$-ray spectrometer system (EDAX) were done before and after adsorption and they are presented in Fig. 3a, b. In the EDAX spectrum, the elements like sodium, magnesium, silica, sulfur, chloride, potassium, calcium, iron and bromine were present along with carbon and oxygen. EDAX proves the presence of fluoride ion after adsorption which confirms the fluoride sorption (Karthikeyan et al. 2009).

\section{BET/CHNO analysis}

Surface area and total pore volume of the adsorbent PDPC estimated as $54.808 \mathrm{~m}^{2} / \mathrm{g}$ and $0.027001 \mathrm{~cm}^{3} / \mathrm{g}$. The surface areas for different adsorbent used for the removal of fluoride along with their particle size were presented in Table 4 . The sorbents like calcite, quartz, fluorspar, hydroxyapatite and 

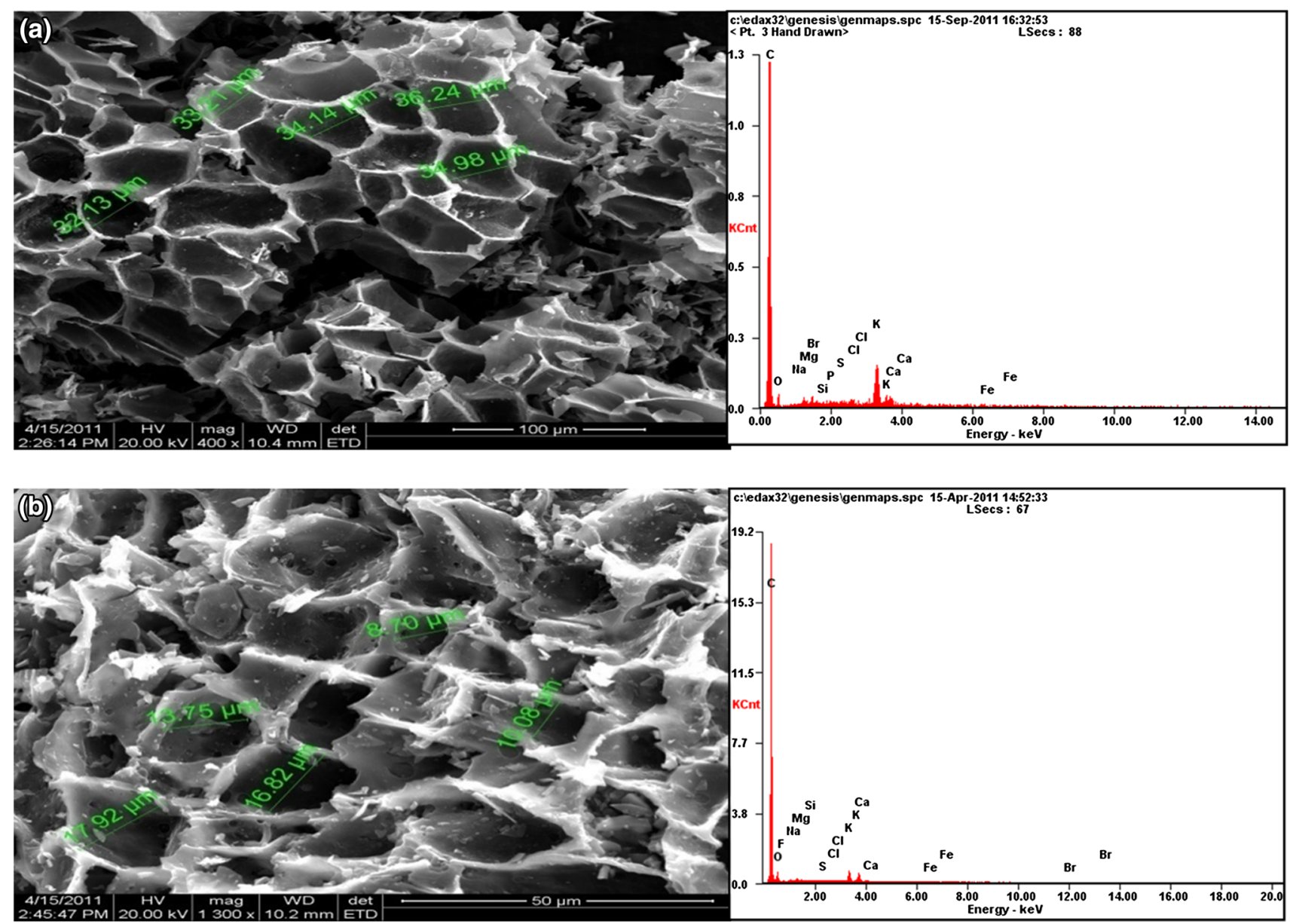

Fig. 3 SEM and EDAX $\mathbf{a}$ before and $\mathbf{b}$ after adsorption of fluoride on PDPC

$\mathrm{MgO}$ composite of particle size between 215 and $250 \mu \mathrm{m}$ has surface area lesser than PDPC. Manganese oxide with GAC, plain GAC, alum-impregnated activated alumina and unimpregnated activated alumina of particle size ranging from 76 to $500 \mu \mathrm{m}$ has larger surface area than PDPC. The agriculture waste products like uncoated rice husk ash (RHA) of $92 \mu \mathrm{m}$ particle size has surface area of $62.8 \mathrm{~m}^{2} / \mathrm{g}$ and aluminum hydroxide-coated rice husk ash (AH-coated RHA) of particle size $108 \mu \mathrm{m}$ has surface area of $50.4 \mathrm{~m}^{2} / \mathrm{g}$. The surface area of PDPC of particle size $424 \mu \mathrm{m}$ has a better surface area when compared to the particle size of RHA, AH-coated RHA.

\section{Adsorption isotherm}

Adsorption isotherm is an important physicochemical phase for determining the adsorption process as a unit operation. Equilibrium studies give the adsorption capacity of the adsorbent and also the suitable model which is required for designing an adsorption system. In this study, isotherms like Freundlich, Langmuir, Temkin and Dubinin-Radushkevich were tried to fit the observed data.

Freundlich isotherm is an indicative of surface heterogeneity and not restricted monolayer formation (Chatterjee and Woo 2009). The linearized form of the isotherm is given as

$\log q_{e}=\log K_{f}+1 / n\left(\log C_{e}\right)$

where $q_{e}$ is the amount of fluoride ion absorbed per unit weight of adsorbent $(\mathrm{mg} / \mathrm{g}), C_{e}$ is the equilibrium concentration of adsorbate in solution after adsorption $(\mathrm{mg} / \mathrm{L})$, $C_{i}$ is the initial fluoride concentration $(\mathrm{mg} / \mathrm{L})$.

$K_{f}$ and $1 / n$ are Freundlich constants related to adsorption capacity and intensity. $K_{f}$ represents the 
Table 4 Characteristic details of various adsorbents with adsorption with fluoride ion as adsorbate

\begin{tabular}{|c|c|c|c|c|}
\hline Adsorbent & Particle size & $\operatorname{BET}\left(\mathrm{m}^{2} / \mathrm{g}\right)$ & Pore volume $\left(\mathrm{cm}^{3} / \mathrm{g}\right)$ & References \\
\hline 1. a) Uncoated rice husk ash & $92 \mu \mathrm{m}$ & 62.8 & - & Ganvir and Das (2011) \\
\hline b) Aluminum hydroxide-coated rice husk ash & $108 \mu \mathrm{m}$ & 50.4 & - & \\
\hline 2. a) Calcite & $215-250 \mu \mathrm{m}$ & 0.057 & - & Fan et al. (2003) \\
\hline b) Quartz & & 0.060 & - & \\
\hline c) Fluorspar & & 0.048 & - & \\
\hline d) Hydroxyapatite & & 0.052 & - & \\
\hline 3. $\mathrm{MgOC}$ composite & - & 45.5143 & - & Sairam Sundaram et al. (2009) \\
\hline 4. a) Manganese oxide with GAC & $450-900 \mu \mathrm{m}$ & 914.17 & $0.509-0.803$ & Yue Ma et al. (2009) \\
\hline b) Plain GAC & & 850.60 & & \\
\hline 5. a) Alum-impregnated activated alumina & $96 \mu \mathrm{m}$ & 176 & & Tripathy et al. (2006) \\
\hline b) Unimpregnated activated alumina & & 113 & & \\
\hline 6. Dried alum sludge & $100 \mu \mathrm{m}$ & 119.4 & & Sujana et al. (1998) \\
\hline 7. Activated alumina & $2,000-5,000 \mu \mathrm{m}$ & 250 & 0.420 & Ghorai and Pant (2005) \\
\hline 8. Zirconium-impregnated groundnut shell & $>53 \mu \mathrm{m}$ & 2.12 & & Alagumuthu and Rajan (2010a, b) \\
\hline 9. Zirconium-impregnated cashew nut shell & $53 \mu \mathrm{m}$ & - & & Alagumuthu and Rajan (2010a, b) \\
\hline 10. Fe(III)-loaded ligand exchange cotton cellulose & 20-40 mesh & 2.23 & & Zhao et al. (2008) \\
\hline 11. $\mathrm{GC}\left(\mathrm{FeSO}_{4} \cdot 7 \mathrm{H}_{2} \mathrm{O}\right)$ & $50-75 \mu \mathrm{m}$ & 80.94 & 0.118 & Chen et al. (2011a) \\
\hline $\mathrm{GC}\left(\mathrm{Fe}_{2} \mathrm{O}_{3}\right)$ & & 50.01 & 0.101 & \\
\hline 12. PDPC & $424 \mu \mathrm{m}$ & 54.808 & 0.027 & Present study \\
\hline
\end{tabular}

quantity of fluoride adsorbed on to PDPC for a unit equilibrium concentration and is defined as the adsorption or distribution coefficient (Tembhurkar and Dongre 2006). A linearized plot of $\log q_{e}$ versus $\log C_{e}$ yields a straight line which has a slope and intercept which correspond to $1 / n$ and $K_{f}$ for various temperature 303 , 313,323 and $333 \mathrm{~K}$.

Langmuir isotherm assumes monolayer adsorption to a surface with a finite number of adsorption sites. The linear form of Langmuir isotherm is given as

$C_{e} / q_{e}=1 / Q_{0} b+C_{e} / Q_{0}$

$Q_{0}$ and $b$ is Langmuir constants related to the affinity of the binding sites, that is, the adsorption capacity and rate of adsorption (Ghorai and Pant 2005). The linear plot of $C_{e} / q_{e}$ versus $C_{e}$ indicates the Langmuir adsorption isotherm with the respective equations for temperature of $303,313,323$ and $333 \mathrm{~K}$. The Langmuir constants $Q_{0}$ and $b$ is obtained from the slope and intercept.

Temkin adsorption isotherm shows the indirect adsorbate/adsorbate interactions. The heat of adsorption of all molecules in the layer would decrease linearly due to adsorbate/adsorbate interaction (Sairam sundaram et al. 2009).

The linearized form of Temkin equation was,

$q_{e}=a_{1}+2.3 b_{1} \log C_{e}$

where $a_{1}$ and $b_{1}$ were Temkin isotherm constants related to adsorption capacity and intensity were obtained by plotting $q_{e}$ versus $\log C_{e}$ (Muthukumaran and Beulah 2011). The values of $a_{1}$ and $b_{1}$ value can be calculated from the intercept and slope. The corresponding equation was also given for different temperature conditions.

Dubinin-Radushkevich isotherm gives an idea about adsorption mechanism and adsorption type. Linear form of D-R isotherm,

$\ln q_{e}=\ln q_{m}-B \varepsilon^{2}$

where $B$ is a constant related to mean free energy of adsorption per mole of the adsorbate $\left(\mathrm{mol}^{2} / \mathrm{J}^{2}\right), q_{m}$ is the theoretical saturation capacity ( $\mathrm{mol} / \mathrm{g}), \varepsilon$ is the Polany's potential, the work required to remove a molecule/ion away from its location in the sorption space.

$\varepsilon=R T \ln \left[1+1 / C_{e}\right]$

$R$ is a gas constant $8.314(\mathrm{~J} / \mathrm{mol} \mathrm{K})$ and $T$ is the absolute temperature in Kelvin (Hasany and Ahmed 2006; Li et al. 2008; Ofomaja 2010). Energy parameter which determines the adsorption mechanism as chemical ion exchange or physical adsorption can be computed using the following equation.

$E=1 / \sqrt{ } 2 B$

If the value of $E$ is $<8 \mathrm{~kJ} / \mathrm{mol}$, it is said to be physical adsorption. If the value of $E$ is between 8 and $16 \mathrm{~kJ} / \mathrm{mol}$, it is said to be the exchange of ions (Islam and Patel 2007). The Dubinin-Radushkevich isotherm plot is $\ln q_{e}$ versus $\varepsilon^{2}$, 
Table 5 Isotherm constants and correlation coefficient for adsorption of fluoride on PDPC

\begin{tabular}{|c|c|c|c|c|c|c|c|c|c|c|}
\hline \multirow[t]{2}{*}{ Temperature (K) } & & \multicolumn{6}{|c|}{ Freundlich } & \multicolumn{3}{|c|}{ Langmuir } \\
\hline & & $1 / n$ & & $n$ & & $K_{f}$ & $R^{2}$ & $b$ & $Q_{o}$ & $R^{2}$ \\
\hline 303 & & 0.885 & & 1.12 & & 33.34 & 0.978 & 1.84 & 28.57 & 0.563 \\
\hline 313 & & 0.985 & & 1.015 & & 55.98 & 0.996 & 0.42 & 125 & 0.209 \\
\hline 323 & & 0.823 & & 1.215 & & 47.97 & 0.946 & 5.99 & 18.52 & 0.657 \\
\hline \multirow[t]{3}{*}{333} & & 0.982 & & 1.018 & & 107.15 & 0.977 & 0.87 & 142.86 & 0.023 \\
\hline & \multicolumn{5}{|l|}{ Temkin } & & \multicolumn{4}{|c|}{ Dubinin-Radushkevich } \\
\hline & $a_{1}$ & & $b_{1}$ & & $R^{2}$ & & $B$ & $q_{m}$ & $E$ & $R^{2}$ \\
\hline 303 & 11.33 & & 2.88 & & 0.968 & & $3 \mathrm{E}+08$ & 12.23 & 0.25 & 0.987 \\
\hline 313 & 12.99 & & 3.19 & & 0.970 & & $3 \mathrm{E}+08$ & 15.29 & 0.25 & 0.998 \\
\hline 323 & 12.82 & & 2.77 & & 0.992 & & $2 \mathrm{E}+08$ & 14.68 & 0.25 & 0.971 \\
\hline 333 & 15.02 & & 3.16 & & 0.930 & & $2 \mathrm{E}+08$ & 19.92 & 0.25 & 0.978 \\
\hline
\end{tabular}

in which, the slope and intercept corresponds to $B$ and $q_{m}$ values.

The values of the intercept and slope and their correlation coefficient were presented in Table 5. In Freundlich isotherm, the value of $K_{f}$ increases with temperature, which indicates that the fluoride adsorption increases with the rise in temperature. The characteristic Freundlich adsorption intensity constant $(1 / n)$ was less than one for all the temperature which implies that the adsorption capacity is higher, favorable and stronger bond between adsorbate and adsorbent (Hasany and Ahmed 2006). The high correlation coefficient $R^{2}$ ranging from 0.946 to 0.996 , clearly indicate the multilayer adsorption.

In Langmuir isotherm, the adsorption capacity $Q_{0}$ value obtained from the slope was $28.57 \mathrm{mg} / \mathrm{g}$ at $303 \mathrm{~K}$, and at higher temperature, the value gets increased. The rate of adsorption obtained from the intercept lies between 0.42 and 5.99. The adsorption efficiency is predicted by dimension less parameter $R_{L}$

$R_{L}=1 /\left(1+b C_{i}\right)$

The calculated $R_{L}$ value for the temperature 303, 313, 323 and $333 \mathrm{~K}$ under various initial fluoride ion concentrations satisfy the condition $\left(0<R_{L}<1\right)$ (Namasivayam and Suresh Kumar 2008). However, from Table 5, the data are not well fitted with the Langmuir isotherm. In general, the data are having minimum value of $R^{2} 0.023$ and maximum value of 0.657 indicating that monolayer adsorption is not much favorable, however, multilayer was favorable which was confirmed by Freundlich isotherm.
In Temkin Isotherm, values of $a_{1}$ and $b_{1}$ obtained from the intercept and slope was found to be increasing for all temperatures which show favorable adsorption. In D-R isotherm, the adsorption capacity, energy constant and mean free energy of adsorption is represented in Table 5. The value of $E$ in D-R isotherm was $0.25 \mathrm{~kJ} / \mathrm{mol}$ for all temperatures which was less than $8 \mathrm{~kJ} / \mathrm{mol}$; hence, the adsorption was physical in nature (Islam and Patel 2007). From Table 5, it can be seen that the correlation coefficient $R^{2}$ value lies between 0.971 and 0.998 .

The temperature effect is a favorable factor for fluoride adsorption, but the irregularity in isotherm values during the raise of temperature was observed for PDPC. Related effect was observed for neodymium-modified chitosan, granular ceramic for defluoridation (Yao et al. 2009; Chen et al. 2010). Though, D-R and Freundlich isotherm has good correlation coefficient, it was observed that Freundlich adsorption capacity was higher than D-R isotherm; hence, Freundlich isotherm is considered to be the best fit.

Adsorption thermodynamics and kinetics study

Temperature is an important parameter in sorption process. The sorption of fluoride on PDPC was observed for 303, 313, 323 and $333 \mathrm{~K}$ under the optimized condition. The values of standard free energy change $\Delta G^{\mathrm{o}}$, enthalpy change $\Delta H^{\mathrm{o}}$ and entropy change $\Delta S^{\mathrm{o}}$ were determined using the following thermodynamics equation

$\ln K_{\mathrm{d}}=\Delta S^{o} / R-\Delta H^{o} / R T$ 
Table 6 Thermodynamic and kinetics, intraparticle diffusion rate constants for adsorption of fluoride on PDPC

\begin{tabular}{|c|c|c|c|c|c|}
\hline \multicolumn{4}{|l|}{ Thermodynamic parameters } & \multicolumn{2}{|r|}{ PDPC } \\
\hline \multicolumn{6}{|l|}{$\Delta G^{\mathrm{o}}(\mathrm{kJ} / \mathrm{mol})$} \\
\hline \multicolumn{5}{|l|}{$303 \mathrm{~K}$} & $-10,376.4$ \\
\hline \multicolumn{5}{|l|}{$313 \mathrm{~K}$} & $-11,478.1$ \\
\hline \multicolumn{5}{|l|}{$323 \mathrm{~K}$} & $-12,394.6$ \\
\hline \multicolumn{5}{|l|}{$333 \mathrm{~K}$} & $-14,194.1$ \\
\hline \multicolumn{4}{|l|}{$\Delta H^{\mathrm{o}}(\mathrm{kJ} / \mathrm{mol})$} & & 27,224 \\
\hline \multicolumn{4}{|l|}{$\Delta S^{\mathrm{o}}(\mathrm{kJ} / \mathrm{mol} \mathrm{K})$} & & \multirow[t]{3}{*}{123.7} \\
\hline \multirow[t]{2}{*}{ Reversible first-order kinetics } & $K=k_{1}+k_{2}\left(\min ^{-1}\right)$ & $k_{1}\left(\min ^{-1}\right)$ & $k_{2}\left(\min ^{-1}\right)$ & $R^{2}$ & \\
\hline & 0.031 & 0.03 & 0.001 & 0.890 & \\
\hline \multirow[t]{2}{*}{ Pseudo-first order } & $q_{e}(\exp )(\mathrm{mg} / \mathrm{g})$ & $q_{e}($ theo $)(\mathrm{mg} / \mathrm{g})$ & $K_{1}\left(\min ^{-1}\right)$ & $p$ & $R^{2}$ \\
\hline & 9.9963 & 2.40 & 0.020 & 75.99 & 0.965 \\
\hline \multirow[t]{2}{*}{ Pseudo-second order } & $q_{e}(\exp )(\mathrm{mg} / \mathrm{g})$ & $q_{e}($ theo $)(\mathrm{mg} / \mathrm{g})$ & $K_{2}(\mathrm{~g} / \mathrm{mg} \min )$ & $p$ & $R^{2}$ \\
\hline & 9.9963 & 10.20 & 0.022 & 2.03 & 0.999 \\
\hline Intraparticle diffusion rate curve & $K_{p \mathrm{i}}\left(\mathrm{mg} / \mathrm{gh}^{1 / 2}\right)$ & & $C_{i}$ & $R^{2}$ & \\
\hline First stage & $K_{p 1}=0.389$ & & $C_{1}=8.843$ & 0.992 & \\
\hline Second stage & $K_{p 2}=0.892$ & & $C_{2}=8.439$ & 0.950 & \\
\hline Third stage & $K_{p 3}=0.029$ & & $C_{3}=9.930$ & 0.751 & \\
\hline
\end{tabular}

where $R$ is a universal gas constant $8.314(\mathrm{~J} / \mathrm{mol} \mathrm{K})$ and $T$ is the absolute temperature in Kelvin.

$K_{\mathrm{d}}$ is the distribution coefficient which is determined by $K_{\mathrm{d}}=C_{\mathrm{ae}} / C_{e}$

where $C_{\mathrm{ae}}=$ amount of fluoride adsorbed on solid at equilibrium $(\mathrm{mg} / \mathrm{L}), C_{e}=$ equilibrium concentration $(\mathrm{mg} /$ L), $\Delta G^{\mathrm{o}}$ was calculated using the equation,

$\Delta G^{o}=-R T \ln K_{\mathrm{d}}$

Gibbs free energy change can be calculated from the equation (Shah et al. 2009)

$\Delta G^{o}=\Delta H^{o}-T \Delta S^{o}$

Enthalpy change $\Delta H^{\mathrm{o}}$ and entropy change $\Delta S^{\mathrm{o}}$ were determined by slope and intercept of a plot of $\Delta G^{\mathrm{o}}$ versus $T$ (Tan et al. 2008; Mario et al. 2008; Meenakshi Sundaram et al. 2011). The values obtained are given in Table 6 .

The kinetics of adsorption was studied using the following equation (Muthukumaran and Beulah 2011) for the different contact time from the batch studies.

Reversible first order, $\ln \left(1-U_{t}\right)=-K t$

$U_{t}=x / x_{e}$ is the fractional attainment of equilibrium, $K$ is the overall rate constant, $t$ is time in minutes, $x_{e}$ is the concentration of fluoride ion adsorbed at equilibrium, $x$ is the amount transferred from liquid phase to solid phase at any time $t$ $x / x_{e}=C_{i}-C_{t} / C_{i}-C_{e}$

$K=k_{1}+k_{2}$,

where, $k_{\mathrm{c}}=k_{1} / k_{2}=x_{\mathrm{e}} / C_{i}-\mathrm{x}_{\mathrm{e}}$.

$C_{i}$ is the initial concentration of fluoride ion, $C_{t}$ is the concentration of fluoride at any time $(t), C_{e}$ is the concentration of fluoride ion present at equilibrium condition. $k_{1}$ and $k_{2}$ represent the forward and backward reaction rate constant.

Pseudo first order, $\ln \left(q_{e}-q_{t}\right)=\ln q_{e}-K_{1} t$

$q_{e}$ is the amount of fluoride adsorbed at equilibrium $(\mathrm{mg} / \mathrm{g})$, $q_{t}$ it is the amount of fluoride adsorbed at time $t(\mathrm{mg} / \mathrm{g}), q_{e}$ (exp) is the experimental data of fluoride adsorbed in equilibrium, $q_{e}$ (theo) is the theoretical value of fluoride adsorbed in equilibrium and $K_{1}$ is the pseudo-first-order constant.

The percent relative deviation $(P)$ is used to calculate and compare the quantitative applicability of kinetic models; the percent relative deviation is calculated using the following equation.

$P=100 / N \Sigma\left[q_{e}(\exp )-q_{e}(\right.$ theo $\left.) / q_{e}(\exp )\right]$

The fit may be considered as excellent if the value of $P$ is less than 5 .

Pseudo second order, $t / q_{t}=1 / K_{2} q_{e}^{2}+t / q_{e}$ 


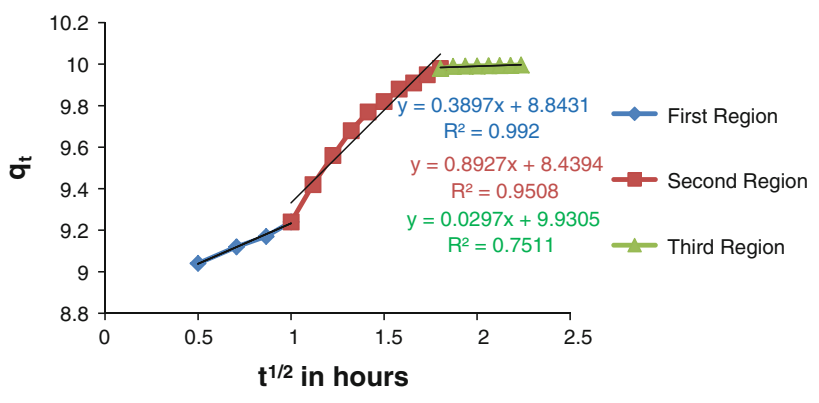

Fig. 4 Intraparticle diffusion model of PDPC on fluoride removal

$K_{2}$ is the pseudo-second-order adsorption rate constant (g/mg/min).

The plots of reversible first-order kinetics with $\log \left(1-U_{t}\right)$ versus $t$, pseudo-first order of $\log \left(q_{e}-q_{t}\right)$ versus $t$ showed correlation coefficient 0.890 and 0.965 and higher $P$ value. When pseudo-second-order equation is used to correlate the data, the value of $R^{2}$ works to 0.999 which is close to unity and also the $P$ value is less than 5 which confirms the applicability of pseudo-second order. The values of the above kinetics are presented in Table 6.

The negative values of $\Delta G^{\mathrm{o}}$ prove that fluoride adsorption is spontaneous (Munagapati et al. 2009). The positive value of $\Delta H^{\mathrm{o}}$ shows that the reaction is endothermic and the positive value of $\Delta S^{\mathrm{o}}$ shows the increased randomness at adsorbent/adsorbate adsorption during adsorption and also it is irreversible and stable (Tan et al. 2008; Sairam Sundaram et al. 2009). It is also evident that negative value of $\Delta G^{\mathrm{o}}$ increases as the temperature increased, this shows that a good driving force resulting in more adsorption capacity.

Intraparticle diffusion model and Boyd model

Intraparticle diffusion model was performed to know the diffusion mechanism which was based on the theory proposed by Weber and Morris (Tan et al. 2008). The removal varies proportionally with $t^{1 / 2}$ other than the contact time $(t)$.

The equation is as follows,

$q_{t}=K_{p} \mathrm{i} t^{1 / 2}+C_{i}$

where $K_{p \mathrm{i}}$ is the intraparticle diffusion rate constant in $(\mathrm{mg} /$ $\left.\mathrm{gh}^{1 / 2}\right)$.

Figure 4 shows the intraparticle diffusion model $q_{t}$ versus $t^{1 / 2}$ in hours to identify the adsorption mechanism. By plotting the graph, it is possible to obtain $K_{p \mathrm{i}}$ value from the slope and $C_{i}$ value from the intercept (Hameed et al. 2008).

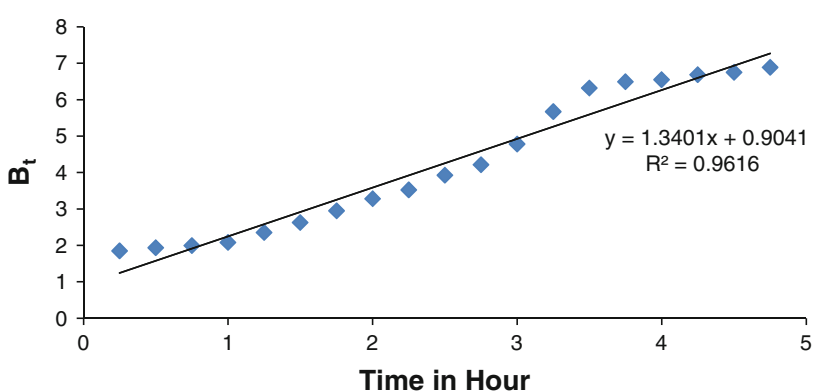

Fig. 5 Boyds model of PDPC on fluoride removal

As the plot is not linear, the whole figure reflects a three stage nature with initial and intermediate linear and final a plateau. The first region shows an external surface adsorption was fast for the first $60 \mathrm{~min}$ as the line is sharper. The second region is gradually rising which shows the intraparticle diffusion is the rate-limiting step which continued up to $195 \mathrm{~min}$. The third region shows the intraparticle diffusion starts to slow down which is the final equilibrium stage due to low adsorbate concentration left in the solution. Similar effect of intraparticle diffusion was observed for granular ceramic (Chen et al. 2010). The values of $K_{p i}, C_{i}$, and $R^{2}$ are given in Table 6 which was obtained from the Eq. (20).

From Table 6 and Fig. 5, it was found that the diffusion is particle diffusion, where the adsorbate ion travels within the pores of the adsorbent excluding a small amount of adsorption that occurs on the exterior surface of the adsorbent.

In order to determine the actual slow step involved in the adsorption process, Boyd model was used using the equation

$F=1-\left(6 / \Pi^{2}\right) \exp \left(-B_{t}\right)$

where $F=q_{t} / q_{0}, q_{0}$ is the amount of fluoride adsorbed at infinite time $(\mathrm{mg} / \mathrm{g}), q_{t}$ is the amount of fluoride adsorbed at any time $t(\mathrm{mg} / \mathrm{g}), F$ is the fraction of solute adsorbed at any time $t$ and $B_{t}$ is the mathematical function of $F$.

The equation gets its simplified form as,

$B_{t}=-0.4977-\ln (1-F)$

Figure 5 shows Boyd model plotted between $B_{t}$ versus $t$ (h) to determine the actual slow step in adsorption. The correlation coefficient value is 0.965 and the line does not pass through the origin; hence, the adsorption is governed by external mass transport; here the particle diffusion was the rate-limiting step, and same trend was seen in TCP on 
prepared coconut husk-based activated carbon which was studied by Hameed et al. (2008).

PDPC of particle size $424 \mu \mathrm{m}$, pore volume of $0.027001 \mathrm{~cm}^{3} / \mathrm{g}$ and surface area of $54.808 \mathrm{~m}^{2} / \mathrm{g}$ has an adsorption capacity of $33.34 \mathrm{mg} / \mathrm{g}$, where as the adsorbents granular ceramic $\left(\mathrm{FeSO}_{4} \cdot 7 \mathrm{H}_{2} \mathrm{O}\right)$, granular ceramic $\left(\mathrm{Fe}_{2} \mathrm{O}_{3}\right)$ having surface areas 80.94 and $50.01 \mathrm{~m}^{2} / \mathrm{g}$, pore volumes 0.1176 and $0.1008 \mathrm{~cm}^{3} / \mathrm{g}$ have shown an adsorption capacity of 2.16 and $1.70 \mathrm{mg} / \mathrm{g}$ (Chen et al. 2011a). From the comparison, it can be inferred that PDPC can be used as an excellent adsorbent for fluoride removal.

\section{Real water sample study}

The water sample collected from Sirunadar Kudieruppu, Udangudi Block, Thoothukudi District, was taken for analysis which had an initial fluoride concentration of $4.8 \mathrm{mg} / \mathrm{L}$. The sample was analyzed using batch process with the optimized condition to confirm its applicability. The initial $\mathrm{pH}$ of the sample was 7.62 that was adjusted to 2 before treatment, using $1 \mathrm{~N} \mathrm{HCL}$. After the treatment, it was found fluoride removal was $97.5 \%$ and at the same time the $\mathrm{pH}$ has increased by 4.2. The other parameters like chloride, alkalinity, TDS, hardness, sulfate and conductivity concentrations which were $1,439.55,744,2,850,372,20.7 \mathrm{mg} / \mathrm{L}$ and $3.3 \mathrm{~ms} / \mathrm{cm}$ before treatment got reduced by $458,247,956,130$, $7.8 \mathrm{mg} / \mathrm{L}$ and $1.2 \mathrm{~ms} / \mathrm{cm}$ after treatment with PDPC, respectively. From the above decrease in concentration values, PDPC proves to be an excellent adsorbent for removing fluoride ion from water.

\section{Conclusion}

In this study, the possibility of utilization of PDPC as an adsorbent for removing fluoride from the aqueous solution was performed. This simple method of batch study revealed a great potential for defluoridation. Maximum fluoride removal was observed at $1.5 \mathrm{~g}$ dosage with a $\mathrm{pH}$ of 2 and contact time of 300 min from equilibrium studies. Interference of co-ions has shown no significant effect on fluoride removal. FTIR, EDAX techniques confirmed that fluoride was successfully adsorbed on PDPC. The sorption process follows Freundlich isotherm indicating multilayer sorption which had a maximum adsorption capacity of $33.4 \mathrm{mg} / \mathrm{g}$ at $303 \mathrm{~K}$ and $107.15 \mathrm{mg} / \mathrm{g}$ at $333 \mathrm{~K}$ and hence proves to be a better adsorbent at higher temperature, which was rarely reported for biosorbent for fluoride removal. Thermodynamic parameters show the adsorption process was spontaneous, irreversible, stable and endothermic. The adsorption kinetics follows pseudosecond order with very high correlation coefficient of 0.999. Adsorption mechanism was governed by external mass transport and particle diffusion was the rate-limiting step. PDPC is capable of maintaining high fluoride adsorption over an acidic $\mathrm{pH}$ range, so it will be useful in removing fluoride ion from polluted water or wastewater of lower pH. Hence, PDPC, a waste material from Delonix regia tree, will be a promising adsorbent for fluoride removal.

Acknowledgments The authors are thankful to Dr. V. Lakshmi Prabha, Ph.D., Principal and Dr. K. Ganesan, Head of Civil Engg. Dept for their kind permission to do this project work at Government College of Engineering, Tirunelveli. They extend their thanks to SAIF IIT, Madras and ANJAC, Sivakasi for analyzing the samples.

\section{References}

Adhikary SK, Tipnis UK, Harkare WP, Govindan KP (1989) Defluoridation during desalination of brackish water by electrodialysis. Desalination 71(3):301-312

Alagumuthu G, Rajan M (2008) Monitoring of fluoride concentration in ground water of Kadayam Block of Tirunelveli District, India. Rasayan J Chem 4:757-765

Alagumuthu G, Rajan M (2010a) Equilibrium and kinetics of adsorption of fluoride onto Zirconium impregnated cashew nut shell carbon. Chem Eng J 158(3):451-457

Alagumuthu G, Rajan M (2010b) Kinetics and equilibrium studies on fluoride removal by Zirconium (IV) impregnated groundnut shell carbon. Hem Ind 64(4):295-304

American Public Health Association, American Water Works Association and Water Environment Federation, Washington, 21st Edition (2005) Standard methods for the examination of water and wastewater

Bhatnagar A, Kumar E, Sillanpaa M (2011) Fluoride removal from water by adsorption-A review. Chem Eng J 171(3):811-840

Chatterjee S, Woo SH (2009) The removal of nitrate from aqueous solutions by Chitosan hydrogel beads. J Hazard Mater 164(2-3):1012-1018

Chen N, Zhang Z, Feng C, Sugiura N, Li M, Chen R (2010) Fluoride removal from water by granular ceramic adsorption. J Colloid Interf Sci 348(2):579-584

Chen N, Zhang Z, Feng C, Li Miao, Zhu D, Sugiura N (2011a) Studies on fluoride adsorption of iron-impregnated granular ceramics from aqueous solution. Mat Chem Phys 125(1-2): 293-298

Chen N, Zhang Z, Feng C, Li M, Chen R, Sugiura N (2011b) Investigations on the batch and fixed bed column performance of 
fluoride adsorption by Kanuma mud. Desalination 268(1-3): $76-82$

Chen L, He B-Y, He S, Wang T-J, Su C-L, Jin Y (2012) Fe-Ti oxide nano-adsorbent synthesized by co-precipitation for fluoride removal from drinking water and its adsorption mechanism. Powder Tech 227:3-8

Fan X, Parker DJ, Smith MD (2003) Adsorption kinetics of fluoride on low cost materials. Water Res 37(20):4929-4937

Ganvir V, Das K (2011) Removal of fluoride from drinking water using aluminium hydroxide coated rice husk ash. J Hazard Mater 185(2-3):1287-1294

George S, Pandit P, Gupta AB (2010) Residual aluminium in water defluoridated using activated alumina adsorption-modelling and simulation studies. Water Res 44(10):3055-3064

Ghorai S, Pant KK (2005) Equilibrium, kinetics and breakthrough studies for adsorption of fluoride on activated alumina. Sep Purif Tech 42(3):265-271

Gonzalez MH, Araujo GCL, Pelizaro CB, Menezes EA, Lemos SG, de Sousa GB, Nogueira ARA (2008) Coconut coir as biosorbent for $\mathrm{Cr}(\mathrm{VI})$ removal from laboratory waste water. J Hazard Mater 159(2-3):252-256

Hameed BH, Tan IAW, Ahmad AL (2008) Adsorption isotherm kinetic modeling and mechanisms of 2,4,6 trichlorophenol on coconut husk based activated carbon. Chem Eng J 144(2):235-244

Hasany S, Ahmed R (2006) The potential of cost effective coconut husk for the removal of toxic metal ions for environmental protection. J Environ Manag 81(3):286-295

Islam M, Patel RK (2007) Evaluation of removal efficiency fluoride from aqueous solution using quick lime. J Hazard Mater 143(1-2):303-310

Karthikeyan G, Siva Illango S (2007) Fluoride sorption using morringa indica based activated carbon. Iran $\mathrm{J}$ Environ Health Sci Eng 4(1):21-28

Karthikeyan M, Satheeshkumar KK, Elango KP (2009) Defluoridation of water via doping of polyanilines. J Hazard Mater 163(2-3):1026-1032

Karthikeyan M, Gopal V, Elango KP (2010) Adsorption of fluoride ions onto naturally occurring earth materials. JASEM ISSN 1119-8362. J Appl Sci Environ Manag 14(4):90-95

Li W, Zhang L, Peng J, Li N, Zhang S, Guo S (2008) Tobacco stems as a low cost adsorbent for the removal of $\mathrm{Pb}$ (II) from wastewater: equilibrium and kinetic studies. Indus Crops Prod 28(3):294-302

Meenakshi S, Natrayasamy Viswanathan S (2007) Identification of selective ion-exchange resin for fluoride sorption. J Colloid Interf Sci 308(2):438-450

Meenakshi sundaram M, Kannan N, Rejinis J (2011) Removal of mixture of textile basic dyes using low cost Artocarpus heterophyllous seed carbon-a batch adsorption study. IJEP 31(7):580-587

Mungapati VS, Yarramuthi V, Nadavala SK, Alla SR, Abburi K (2009) Biosorption of $\mathrm{Cu}$ (II), Cd (II) and $\mathrm{Pb}$ (II) by Accacia leucocephala bark powder: kinetics, equilibrium and thermodynamics. Chem Eng J 157(2-3):357-365

Murugan M, Subramanian E (2006) Studies on defluoridation of water by tamarind seed, an unconventional biosorbent. J Water Health 044:453-461

Muthukumaran K, Beulah S (2011) Removal of chromium (VI) from waste water using chemically activated syzygium jambolanum nut carbon by batch studies. Procedia Environ Sci 4:266-280
Nadeem R, Ansari TM, Akhtar K, Khalid AM (2009) Pb(II) sorption by pyrolysed pongamia pinnata pods carbon (PPPC). Chem Eng J 152(1):54-63

Namasivayam C, Suresh Kumar MV (2008) Removal of chromium (VI) from water and waste water using surfactant modified coconut coir pith as a biosorbent. Bioresour Technol 99(7):2218-2225

Ofomaja AE (2010) Equilibrium studies of copper ion adsorption onto palm Kernel fibre. J Environ Manag 91(7):1491-1499

Paudyal H, Pangeni B, Ghimire KN, Inoue K, Ohto K, Kawakita H, Alam S (2012) Adsorption behavior of orange waste gel for some rare earth ions and its application to the removal of fluoride from water. Chem Eng J 195-196:289-296

Pehlivan E, Tran HT, Ouedraogo WKI, Schmidt C, Zachmann D, Bahadir M (2013) Sugarcane bagasse treated with hydrous ferric oxide as a potential adsorbent for the removal of $\mathrm{As}(\mathrm{V})$ from aqueous solutions. Food Chem 138(1):133-138

Sairam Sundaram C, Viswanathan N, Meenakshi S (2009) Defluoridation of water using magnesia/chitosan composite. J Hazard Mater 163(2-3):618-624

Shah BA, Shah AV, Singh RR (2009) Sorption isotherms and kinetics of chromium uptake from wastewater using natural sorbent material. Int Environ Sci Tech 6(1):77-90

Shen P (2008) Fluoride removal with extra low energy reverse osmosis membranes: 3 years of large scale field experience in Finland. Desalination 223(1-3):73-84

Sujana MG, Anand S (2011) Fluoride removal studies from contaminated ground water by using bauxite. Desalination 267(2-3):222-227

Sujana MG, Thakur RS, Rao SB (1998) Removal of fluoride from aqueous solution by using alum sludge. J Colloid Interf Sci 206(1):94-101

Tan IAW, Ahamad AL, Hameed BH (2008) Adsorption of basic due on high surface area activated carbon prepared from coconut husk: equilibrium, kinetic and thermodynamic studies. J Hazard Mater 154(1-3):337-346

Tembhurkar AR, Dongre S (2006) Studies on fluoride removal using adsorption process. J Environ Sci Eng 48(3):151-156

Tripathy SS, Bersilloa J-L, Gopal K (2006) Removal of fluoride from drinking water by adsorption on to the alum-impregnated activated alumina. Sep Purif Technol 50(3):310-317

Vennila G, Subramani T, Elango L (2008) GIS based ground water quality assessment of Vattamalikarai Basin, Tamilnadu, India. Environ Pollut Tech 7(4):585-592

Viswanathan G, Jaswanth A, Gopalakrishnan S, Siva ilango S (2008) Mapping of fluoride endemic areas assessment of fluoride exposure. Sci Tot Environ 407(5):1579-15873

Wikipedia.org/wiki/flamboyant-tree flamboyants (Delonix regia) Royal pancianas, Gulmohar, flamboyant tree, peacock flower 048 (2011)

Xiaotin X, Li Q, Cui H, Pang J, Sun L, An H, Zhai J (2011) Adsorption of fluoride from aqueous solution on magnesia loaded fly ash cenospheres. Desalination 272(1-3):233-239

Yao R, Meng F, Zhang L, Ma D, Wang M (2009) Defluoridation of water using neodymium-modified chitosan. J Hazard Mater 165(1-3):454-460

Yue Ma X, Wang S-G, Fan M, Gong W-X, Gao B-Y (2009) Characteristics and defluoridation performance of granular activated carbons coated with manganese oxides. J Hazard Mater 168(2-3):1140-1146

Zhao Y, Li X, Liu L, Chen F (2008) Fluoride removal by Fe(III) loaded ligand exchange cotton cellulose adsorbent from drinking water. Carbohydr Polym 72(1-3):144-150 
Zhao X-T, Zeng T, Hu ZJ, Gao H-W, Zou CY (2012a) Modeling and mechanism of the adsorption of proton onto natural bamboo sawdust. Carbohydr Polym 87(2):1199-1205
Zhao X-T, Zeng T, Li X-Y, Hu ZJ, Gao H-W, Xie Z (2012b) Modeling and mechanism of the adsorption of copper ion onto natural bamboo sawdust. Carbohydr Polym 89(1):185-192 